\title{
Movilidad jesuita en la provincia de México a finales del siglo XVI y principios del siglo XVII. Un análisis desde las biografías individuales de los miembros de la Compañía de Jesús
}

Jesuit moblity in the province of Mexico at the end of the sixteenth century and beginning of the seventeenth. An individual analysis from the biographies of the members of the Society of Jesus

Pablo Abascal Sherwell Raull

Resumen: Estudiar la movilidad de la Compañía de Jesús es una fuente de gran riqueza para entender cómo funcionaban las provincias y las instituciones jesuitas, analizando en este caso la movilidad jesuita en la provincia de México a finales del siglo XVI y principios del XVII. El artículo está dividido en tres partes, analizando en un primer apartado las instituciones y los personajes que manejaban la movilidad del personal de la Compañía de Jesús; un segundo apartado que muestra cómo la movilidad y elección de personal en los centros se elegía según sus necesidades y el momento histórico que estaban viviendo; y por último, se estudia cómo se vivió la movilidad en la provincia de México durante los generalatos de Claudio Acquaviva y Muzio Vitelleschi.

Palabras clave: provincia de México, biografías, movilidad, colegios, misiones.

Abstract: Studying the mobility of the Society of Jesus is a source of great value to understand how the Jesuit provinces and institutions used to function. This article analyzes the Jesuit mobility in the province of Mexico in the late sixteenth and early seven-

*Universidad Autónoma de Querétaro, Querétaro, México. E-mail: abascal_pablo@hotmail.com 
teenth centuries. The article is divided into three sections: the first section analyses the institutions and characters that managed the mobility of personnel of the Society of Jesus; the second section shows how the mobility and selection of personnel was chosen according to the needs of the province and the historical moment it was living; and finally, the third section analyzes how the mobility occurred in the province of Mexico during the generalships of Claudio Acquaviva and Mutio Vitelleschi.

Key words: province of Mexico, biographies, mobility, colleges, missions.

Recibido: 29 de mayo de 2017.

Evaluado: 27 de junio de 2017. 


\section{Introducción}

Desde la realización de mi tesis doctoral, y en las investigaciones que he realizado posteriormente, he analizado que, para entender las instituciones jesuitas en general, y de Nueva España en particular, es necesario estudiar el personal que las conformaban, para poder entender cómo funcionaban. El personal de la provincia de México fue variable, y su selección estaba relacionada con los deseos de los monarcas en España, los generales en Roma, así como la realidad histórica que se vivía en la provincia. La Compañía de Jesús llegó a Nueva España en 1572, con el permiso de Felipe II, en el último año del generalato de Francisco de Borja (1565-1572), comenzando a expandirse con Everardo Mercuriano (1573-1580), y consolidándose durante el generalato de Claudio Acquaviva (1581-1615). El gobierno de este último ha sido ya muy estudiado y debatido, pero para lo que a este artículo interesa, éste fue de suma importancia, ya que vivió una expansión global sin precedentes, aumentando el número de instituciones y la necesidad de personal que las atendieran. ${ }^{1}$

El presente artículo se basa en el primer anexo de mi tesis doctoral, en donde reconstruyo las biografías de los jesuitas que pasaron por el colegio de Tepotzotlán entre 1580 y 1617, siendo 69 en total (Abascal Sherwell, 2015). A partir del material que recopilé, busco analizar cómo estaba conformado el personal de la provincia de México durante el generalato de Claudio Acquaviva (1581-1615) y el tránsito al de Muzio Vitelleschi (1615-1645), a través de la movilidad de los miembros de la Compañía (Maldavsky, 2014).

Decidí tratar este tema, ya que la reconstrucción de las biografías arroja una enorme veta de posibilidades de análisis, que me ha hecho indagar sobre la gran diversidad de personal que existía en las instituciones jesuitas de la provincia de México durante estos dos generalatos, así como su movilidad. Las biografías jesuitas demuestran la gran movilidad que sufrieron sus miembros, ya que en la América española estaban a disposición de su General y del Rey, quienes decidían el lugar al que debían ir a trabajar.

Si bien la primera expedición a Nueva España tenía puros miembros peninsulares (Sánchez Baquero, 1945), esto comenzó a cambiar después, con la llegada de algunos miembros provenientes de otras partes de Europa, y el lento, pero continuo, ingreso de los criollos a la Compañía de Jesús. Por ello, y para estudiar cómo se movía el personal, decidí dividir el artículo en tres partes. La primera versa sobre las reglas, personajes e instituciones que regulaban la movilidad de los jesuitas; la segunda sobre la elección del personal al interior de la Orden; y finalmente, la tercera sobre el movimiento del personal dentro de los colegios de la provincia de México.

\section{El envío a América y el ingreso a la Compañía de Jesús: Reglas, personajes e insti- tuciones:}

Entre los miembros que conformaban la Compañía de Jesús en Nueva España había tres grupos de personas: los peninsulares, los europeos no peninsulares, y los crio-

\footnotetext{
1 Sobre el generalato de Claudio Acquaviva, se recomienda ver Broggio, Cantú (2007). Sobre las fricciones internas al interior de la orden, ver Catto (2009).
} 
llos. Los dos primeros tenían un control muy estricto de envío al nuevo mundo, mientras los últimos tenían más dificultad de ser aceptados en la Orden, debido a su condición de haber nacido en América. La elección de buenos sujetos se consideraba de suma importancia para la evangelización de América, por lo que José de Acosta pedía que el envío de jesuitas a las Indias fuera observado de forma muy rigurosa, ya que "nunca será tan necesaria la advertencia y a nadie hay que exigir tanto esa excelencia como a los que se han encargado de ganar las almas para Cristo con la palabra de Dios, las almas de los infieles y precisamente de los indios". 2

La elección de los jesuitas que eran enviados al nuevo mundo requería un proceso complejo y riguroso, el cual tenía como primera dificultad el ser aceptado en la Orden, según los principios que dictaban las Constituciones. Éstas pedían hacer una elección propia de los candidatos, teniendo en cuenta las habilidades y vocación de los futuros jesuitas, así como la obligación de demostrar ser personas de buena vida y capacidad para el trabajo. ${ }^{3}$

Por su parte, el envío del personal de Europa giraba en torno a las decisiones del gobierno jesuita centralizado de Roma, así como a la necesaria colaboración con el Consejo de Indias, la institución de la Corona española más importante encargada de los asuntos americanos. Ambas instituciones controlaban el número, las cualidades y la formación de quienes debían ser enviados a las Indias, siendo fundamental la autorización de la Corona para pasar a territorios americanos, estableciendo desde 1549, antes de la llegada de la Compañía al nuevo mundo, "que no pasen clérigos ni frailes a las Indias sin licencia del rey". ${ }^{4}$ Fue por ello, que la mayoría de los jesuitas enviados desde Europa a las Indias durante el generalato de Claudio Acquaviva y Muzio Vitelleschi, pertenecían a los reinos de Castilla, aunque también llegaron jesuitas del reino de Aragón y de otros lugares de Europa, sobre todo Italia (Ortega Moreno y Galán García, 2012). Además, a diferencia de las órdenes mendicantes, quienes estaban solamente sujetos a las órdenes del Regio Patronato para su envío a América, los jesuitas dependían también del General de la Compañía, quien tenía la última decisión sobre a qué lugares del mundo enviar a los padres de la Compañía, según lo establecido en las Constituciones. 5

Además, los jesuitas que se embarcarían al nuevo mundo estaban sujetos a los deseos del provincial y lo acordado por las congregaciones provinciales de Nueva España, que por medio de los procuradores de misiones enviados a Roma, informaban al General qué tipo de gente se necesitaba en la provincia, y el General, de acuerdo a lo que se podía ofrecer desde Europa, decidía qué sujetos eran enviados a América. De esta forma, la distribución de los padres de la Compañía de Jesús en las provincias americanas se sometía a las necesidades que pidieran los provinciales, y las decisiones que se tomaban en Roma y España.

Así, para mediar entre las necesidades materiales o de personal de las provincias americanas y lo que Roma podía ofrecer, se creó el Oficio de Indias, instaurado en Sevi-

\footnotetext{
${ }^{2}$ DPIS II, p. 11.

${ }^{3}$ Constituciones, Parte I, Capítulo 2, Punto 142, p. 126; Parte IV, punto 308, pp. 172-173.

${ }^{4}$ RLI Tomo IV, Título XXVI, Ley XI.

${ }^{5}$ Constituciones, Parte VII, Capítulo 2, Punto 618, p. 271.
} 
1la, estando a su mando el Procurador de Indias, quien a su vez estaba sujeto a la autoridad de la provincia de Andalucía, y por lo tanto, del Regio Patronato. Sus principales tareas eran dos: La primera era proveer a las necesidades de las provincias de México y Perú, comprando los materiales necesarios para que se utilizaran en los colegios y misiones de sus respectivas provincias, y la segunda era mediar entre las cartas y otros envíos que se mandaba de Roma a las provincias de indias, así como de las provincias de indias a Roma. ${ }^{6}$ Además, los procuradores de indias tenían prohibido hacer negocios en torno a lo que se les pedía en los colegios americanos, no podían encargarse de forasteros o de gente fuera de la Compañía, tenían prohibido recibir dinero de jesuitas y de parientes, y no podían comparar a su albedrío si no se les había pedido antes en las provincias. ${ }^{7}$ También tenían la función de ser los encargados de proveer de ayuda a los jesuitas mientras estaban en Sevilla, antes de partir a América. ${ }^{8}$

El otro mediador entre América y Roma era el ya mencionado procurador de misiones, quien acudía a Roma después de las Congregaciones provinciales, con el objetivo de informarle al General de la Compañía sobre la situación de sus provincias, además de encargarse también de organizar las nuevas expediciones de vuelta, según lo acordado en las Congregaciones provinciales, aunque Roma ofrecía solamente lo que le era posible. ${ }^{9}$ Un ejemplo de ello lo proporciona el caso de la segunda congregación provincial de México, llevada a cabo en 1585, en la que se pidieron misioneros para la provincia de Michoacán, ya que se acordó la necesidad que había de enviar personal para reducir a los indios. La respuesta de Roma fue que sólo podían enviar a dieciséis hombres, junto con el procurador de misiones, el padre Pedro de Ortigosa. ${ }^{10}$

Por su parte, los criollos sufrieron innumerables dificultades para entrar a la Orden, no sólo debido a que también tenían que pasar los requerimientos que exigían las Constituciones, sino por la gran cantidad de obstáculos que se les impusieron para su ingreso por haber nacido en América. Sin embargo, su ingreso nunca se les prohibió tajantemente, como sí lo sufrieron los indígenas, buscando acceder a puestos de poder dentro de la propia Orden que estaban monopolizados en un principio por los nacidos en la Península Ibérica. A pesar de que comenzaron siendo una minoría dentro de la Orden, su número cada vez fue en aumento, generando tensiones con los peninsulares (Abascal Sherwell, en prensa).

Ya elegidos quiénes eran enviados a Nueva España, y seleccionados los americanos que podían ser aceptados para unirse a la Orden, surgió el problema de cómo distribuir al personal dentro de la provincia. De la misma forma que se escogían jesuitas para las Indias dependiendo lo que pedía cada provincia, hubo un perfil de los jesuitas

\footnotetext{
${ }^{6}$ ARSI, Mex 01, Epp. Gen, 1574-1599, f. 005.

${ }^{7}$ ARSI, Baet. 3, fol. 300r.

${ }^{8}$ Sobre el procurador y el oficio de Indias, se recomienda ver los siguientes estudios: Zubillaga (1953) y Galán García (1995).

${ }^{9}$ Las Constituciones establecían que los Procuradores que se encontraban en Indias debían ir cada cuatro años a dar información a Roma. Constituciones, Parte VIII, Capítulo 2, punto 679, p. 294. En su trabajo, Pedro Borges da otra cifra, diciendo que en realidad era cada seis, (1977, p. 90). No obstante, es posible suponer que el envío de procuradores a Roma no se llevaba a cabo siempre en el tiempo establecido por las Constituciones.

${ }^{10}$ ABZ I p. 539.
}

90 Pablo Abascal Sherwell Raull. Movilidad jesuita en la provincia de México... 86-99. 
que fueron enviados a las misiones o colegios jesuitas según el momento que éstos vivían, sobre lo cual hablaremos a continuación.

\section{La elección del personal en los distintos centros de la provincia}

La movilidad del personal era propia de la Compañía de Jesús, teniendo como objetivo ir a las diferentes regiones del mundo a predicar, ${ }^{11}$ formando entre sus miembros una identidad misionera. Como ya se dijo, los jesuitas eran enviados a las distintas partes del mundo según las necesidades de los padres provinciales y la falta miembros que existía en sus provincias, así como las posibilidades que Roma tenía de enviar misioneros. Por su parte, al aceptar Felipe II que entraran a sus reinos americanos, y conociendo el alto movimiento que existía dentro de la Orden, el rey promulgó una ley en 1572 en la que pedía que no se impidiera a los jesuitas "el ser mudados de unas provincias y colegios a otros". 12

Durante el tiempo que gobernó Claudio Acquaviva, se abrió una gran cantidad de centros jesuitas en la provincia de México, habiendo al momento de su muerte diecinueve, entre los que se encontraban seminarios, misiones, colegios, residencias, y una Casa Profesa. Por ello, y debido al gran movimiento que existía en la provincia, me enfocaré en el caso de Tepotzotlán, debido a que a partir de él pude reconstruir 69 biografías, las cuales aportan conocimiento al dinamismo que existía en la provincia. Además, la otra ventaja de estudiar Tepotzotlán, es que cuando éste se convirtió en noviciado definitivamente en 1606, comenzó a ser un lugar de partida para todos los miembros que entraban a la Compañía, siendo un lugar importante para estudiar quiénes eran los jesuitas de la provincia de México y a qué lugares eran enviados.

De esta forma, podemos observar que el número de jesuitas que residieron en Tepotzotlán tuvo una gran variación desde su fundación en 1580, hasta la muerte de Claudio Acquaviva en 1615. Éste comenzó siendo una residencia dependiente del Colegio Máximo de México en 1580, durante el generalato de Everardo Mercuriano, habiendo sólo cinco jesuitas en 1582 y un seminario de lenguas indígenas; cuando se instauró el seminario de indios de San Martín en 1584, y la instauración de un noviciado en 1586, el número de jesuitas ascendió a nueve. ${ }^{13}$ Aunque el noviciado haya pasado a Puebla por un breve tiempo entre 1591 y 1606, el número de jesuitas aumentó a diez en $1592,{ }^{14}$ y a once en $1594,{ }^{15}$ debido a que durante ese período se intentó instaurar un seminario de humanidades o juniorado en Tepotzotlán, el cual no prosperó, por lo que en 1600 el número de jesuitas disminuyó a diez, ${ }^{16}$ y en 1604 a siete. Pero el noviciado regresó a Tepotzotlán definitivamente en 1606, año en que también Tepotzotlán se independizó del Colegio Máximo y obtuvo la categoría de colegio, habiendo un gran au-

\footnotetext{
${ }^{11}$ Constituciones, Parte IV, Punto 308, pp. 173-174.

${ }^{12}$ RLI, Tomo I, Título 14, Ley XXIII.

${ }^{13}$ ARSI, Mex. 04, fol. 026 r.

${ }^{14}$ ARSI, Mex. 04, fol. 44r- $45 \mathrm{v}$

${ }^{15}$ ARSI, Mex. 04, fol. 66r

${ }^{16}$ ARSI, Mex. 04, fols. 117 v- 118 r.
} 
mento en el número de jesuitas, siendo dieciocho en $1607,{ }^{17}$ y treinta y cuatro en $1614 .^{18}$

De esta forma, observamos que el cambio en el número de personal dependía de las circunstancias que el centro vivía en el momento, habiendo también un cambio en su perfil, como lo demuestra el caso de Tepotzotlán cuando el noviciado pasó a Puebla en 1591, y se buscó establecer un seminario de humanidades en Tepotzotlán entre 1592 y 1595. Fue debido a estos cambios, que en esta época encontramos en este centro a la mayor densidad de jesuitas con estudios en Europa, lo que podía intuirse como el intento de crearse un seminario de muy alto nivel. De los once miembros que había en 1594 , cuatro habían terminado sus estudios en Europa, siendo Juan Laurencio, Francisco Villareal, Antonio Rubio y Francisco de Guzmán. ${ }^{19}$

El caso de Antonio Rubio es revelador, ya que nos muestra el ejemplo de un jesuita que no querían estar en Nueva España y debió atenerse a las disposiciones del General. Se decidió enviarlo a Nueva España en 1576, por las competencias intelectuales que tenía y que hacían falta en el virreinato, destacándose en este ámbito. Inauguró la silla de filosofía en el Colegio Máximo, posteriormente en el año de 1587, estuvo en Tepotzotlán donde hizo su cuarto voto, trabajó sobre la filosofía de Santo Tomás y Aristóteles previo a la publicación final de la Ratio studiorum de 1599, y en 1593 se doctoró en filosofía en la Universidad de México. A pesar del altísimo valor del trabajo intelectual que realizó, y que trascendió la Nueva España para ser leído en Europa, fue constante en pedir a Roma su regreso a España. Decía no estar interesado en ayudar a los indios ni en aprender lenguas indígenas, y afirmaba que iba a servir más a la Compañía estando en España que en Nueva España, ya que el virreinato no le otorgaba las posibilidades académicas europeas. ${ }^{20}$ Por lo anterior, debía esperar la respuesta del General, ya que los jesuitas debían quedarse por un período largo en su lugar de misión, y si querían moverse, después de meditar y considerar las razones donde podían servir mejor a Dios, debían esperar la respuesta del superior. ${ }^{21}$ Su deseo se le concedió, y en 1600 regresó a Roma como procurador de V Congregación Provincial, y en 1602 fue a España, ${ }^{22}$ donde murió en $1615{ }^{23}$ Antonio Rubio no regresó solo a Europa, acompañándolo también los padres Francisco de Guzmán, Diego Ibarra y Pedro Sánchez. ${ }^{24}$

Pero en Tepotzotlán existió un perfil que siempre estuvo presente, el de los padres lengua, debido a que el seminario de lenguas siempre se mantuvo constante y no sufrió crisis, ya que de aquí salían los padres que después iban a misionar en los pueblos de los alrededores, o en las nuevas residencias, misiones y colegios que se estaban abriendo en el área chichimeca, al norte de la Nueva España. ${ }^{25}$ Al llegar a Nueva Espa-

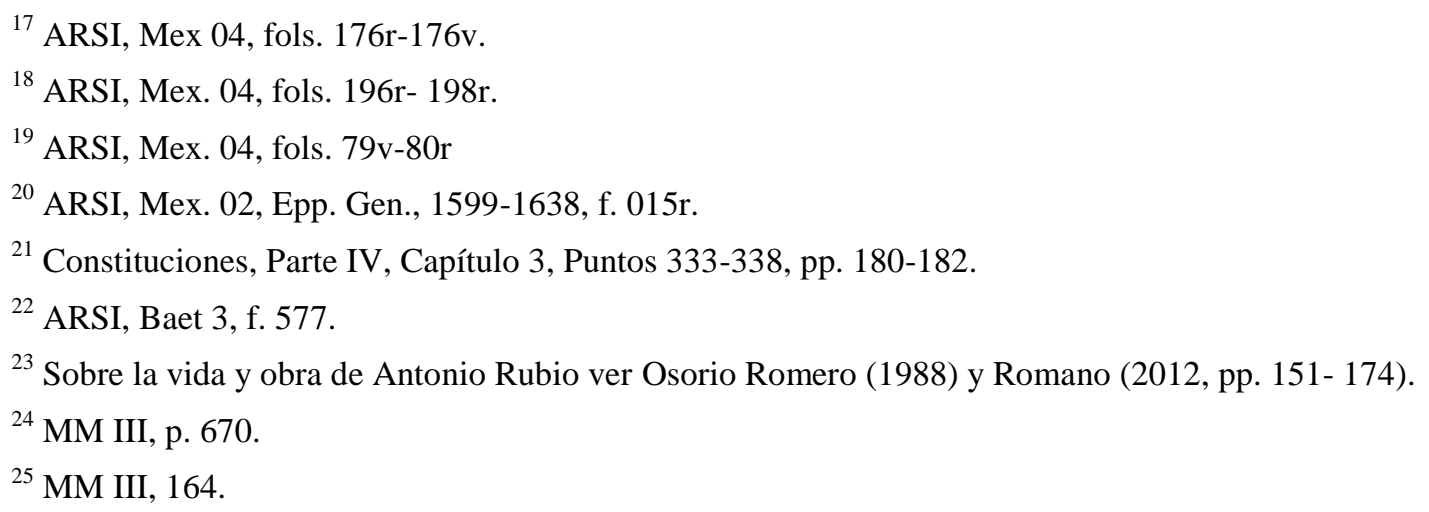


ña, ninguno de los jesuitas traídos de Europa sabía lenguas indígenas, lo cual fue cambiando al paso de los años mientras un número más grande de jesuitas se dedicaba al trabajo con los indios y aprendía las lenguas, además de que más criollos, con el conocimiento de alguna lengua indígena, entraban a la Compañía. ${ }^{26}$ Durante el intento de la instauración del Seminario de humanidades, había en la Residencia de Tepotzotlán diez jesuitas, entre los que también estuvo uno de los novohispanos que más ayudó al estudio de las lenguas indígenas, Antonio del Rincón. ${ }^{27}$

Ya independizado Tepotzotlán del Colegio Máximo, los padres lengua continuaron siendo pedidos constantemente, como lo demuestra la Séptima congregación provincial de 1609, en la que el rector, el padre Francisco Vaez, pidió obreros para gente que aprendiera lengua otomita, por la falta de ministros que existía de ésta. ${ }^{28}$ Fue en esta década que llegaron a Tepotzotlán nuevos jesuitas traídos de Europa a confesar indios en su lengua, como los padres Luis de Ahumada, Francisco Calderón y Horacio Carochi.

El caso de Carochi es ilustrativo, quien fue enviado a Nueva España en la expedición de 1605, en una época que Acquaviva hacía expresa la necesidad de adoctrinar indios, y que hubiera padres lengua. ${ }^{29}$ Así, Carochi se convirtió en un modelo de padre lengua en náhuatl y otomí, ${ }^{30}$ trabajando por más de veinte años en hacer un diccionario de sus vocablos. ${ }^{31}$ Como él, varios de los jesuitas europeos que habían sido enviados a América no habían estado interesados en misionar en este continente, teniendo preferencia por Asia, como lo muestran sobre todo los jesuitas italianos y franceses en las cartas Indipetae (Rusell, 2011; Maldavsky, 2012). Para que los jesuitas dejaran de pedir que los enviaran a lugares en Asia, Andrés Pérez de Ribas escribió a mediados del siglo XVII, Historia de los triunfos de nuestra santa fe entre las gentes más bárbaras y fieras del nuevo orbe, teniendo como uno de sus propósitos convencer a más gente a que fuera a misionar a América (Brading, 1991, p. 176).

A pesar de haber tenido Tepotzotlán una baja de padres lengua cuando el noviciado pasó a Puebla entre 1591 y 1606, siempre fue uno de los centros más numerosos en la provincia de México con este tipo de padres, mostrando desde entonces su vocación en el aprendizaje y enseñanza de náhuatl y otomí. En los catálogos trienales de 1595 , aparece la misma cantidad de padres que hablaban y ejercitaban una lengua indígena en Tepotzotlán, que en los colegios de México y Pátzcuaro, ${ }^{32}$ siendo solamente superado en 1600 por el Colegio Máximo, que tenía doce padres lengua, teniendo Tepotzotlán junto con Guadiana, ocho en total. ${ }^{33}$ También hubo innumerables padres, que

\footnotetext{
${ }^{26}$ Ver cómo cambia el número de padres lengua durante el siglo XVI en Burrus (1956, pp. 574-597).

${ }^{27} \mathrm{MM} \mathrm{V}$, p. 549.

${ }^{28}$ ABZ II, p. 623.

${ }^{29}$ ARSI, Mex. 02, fol. 107r.

${ }^{30}$ ABZ II, p. 649.

${ }^{31}$ ABZ II, p. 662.

${ }^{32}$ ARSI, Mex. 04, fol. 84r-85v.

${ }^{33}$ ARSI, Mex. 04, fol. 134v-135r.
} 
a pesar de no haber querido aprender lenguas indígenas, fueron obligados a hacerlo, como lo demuestra el caso de Antonio Rubio, que siempre fue renuente a aprenderlas. ${ }^{34}$

Si bien nos basamos en Tepotzotlán para analizar cómo eran elegidos los jesuitas para ir a un lugar en específico, podemos intuir que ocurrió algo similar en los demás centros de la provincia, según cambiaba su estatuto y sus necesidades, siendo muy común el cambio de estatus de misiones a colegios durante el generalato de Muzio Vittelleschi.

\section{Movilidad jesuita dentro de la provincia de México}

Como hemos venido diciendo, la movilidad fue una constante en la provincia de México, existiendo no sólo movilidad de padres, sino también de indios entre los centros jesuitas. Cuando en el generalato de Muzio Vitteleschi muchas misiones adquirieron el estatus de colegio, la movilidad de personal continuó en ellos, aunque si bien decreció un poco, no fue un factor determinante para su declive, según nos demuestran las biografías que presentaremos a continuación. A partir de éstas, se observa que muchos jesuitas no se quedaban largos períodos en algún centro específico, yendo a otros continuamente, y habiendo casos en los que pasaban más de una ocasión por algunos de ellos. También hubo casos en los que los jesuitas estuvieron tan poco tiempo en los colegios, que no aparecieron nunca en los catálogos trienales, como el caso del padre Juan de Plaza, quien en 1584 fue nombrado rector de la residencia de Tepotzotlán, en donde sólo estuvo dos meses, debido a que tuvo que participar en el III Concilio Provincial Mexicano de 1585 (Zubillaga, 1961, p. 186). Finalmente, también hubo padres que casi no tuvieron movilidad, sobre todo algunos que estuvieron en la Ciudad de México y sus alrededores, teniendo una sedentarización similar entre los generalatos de Acquaviva y Vitelleschi.

Un ejemplo de constante movilidad y repetición en algunos de los centros, nos lo muestra el padre Nicolás de Arnaya, quien después de haber llegado de España a Nueva España, estuvo primero en la residencia de Tepotzotlán (1585-1588), después fue a inaugurar la misión de Guadiana (1588), regresando unos años después a la residencia de Tepotzotlán (1592-1595), para pasar posteriormente como rector a la recién inaugurada misión de San Luis de La Paz (1596-1598). Años después, volvió a Guadiana como rector a la ahora residencia (1600-1603), y regresó por tercera ocasión al ahora colegio de Tepotzotlán como rector, donde estuvo seis años (1604-1610), siendo posteriormente, entre 1610 y 1613, nombrado rector del colegio del Espíritu Santo, en Puebla. Entre 1613 y 1615 viajó como procurador a Roma, y en 1616, durante el gobierno de Muzio Vitelleschi, fue electo provincial, cargo que tuvo hasta 1622, estando desde entonces en la Ciudad de México, donde murió en $1623 .{ }^{35}$

Otro caso ilustrativo es el de Horacio Carochi, quien se movió sobre todo en el centro de México, y tuvo mayor sedentarización durante el generalato de Vitelleschi. Llegó a Nueva España proveniente de Italia, estuvo en el Colegio Máximo (1605-1609), después fue enviado a la misión de San Luis de la Paz (1610), cuatro años más tarde

\footnotetext{
${ }^{34}$ MM VII, p. 25.

35 ARSI, Mex 04, fol, 27r; DBCJM, III, p. 554; MM VI, p. 152; MM VII, p. 46; MM VIII, p. 392; Diccionario Histórico de la Compañía de Jesús I, p. 236; DBCJM III, p. 555
} 
aparece en Tepotzotlán durante el último año del gobierno de Acquaviva y la mayoría del de Vitteleschi, estableciéndose una larga temporada (1614-1638). Posteriormente fue trasladado al Colegio Máximo, donde se convirtió en socio del provincial (16381645), y después fue elegido rector del Colegio Máximo (1645-1647). Duró poco tiempo en ese puesto, para después pasar a ser el Superior de la Casa Profesa, donde estuvo más de diez años (1647-1653), regresando después a Tepotzotlán como rector (16531655), donde murió en $1662 .^{36}$

Así, a partir de estos dos ejemplos, podemos observar que la movilidad de los jesuitas fue continua, y que éstos habían sido enviados a distintos lugares según las nuevas aperturas de centros y las necesidades de la provincia. En los primeros años después de la apertura de Tepotzotlán, fue de gran importancia la movilidad que se dio en la ruta de la plata y la apertura de la misión de San Luis de la Paz, habiendo no sólo movilidad de jesuitas, sino también de indios. Los padres Francisco Zarfate y Diego de Monsalve fundaron una casa en San Luis de la Paz en 1594, llevando con ellos cuatro indios otomites catequistas de Tepotzotlán, para la escuela de chichimecos que se instaló en el nuevo centro jesuita (Cuevas, 1921, p. 392). A ellos le siguieron el padre Hernán Gómez, que fue con un contingente de indios otomíes cristianos con el fin de "robustecer" a la población (Decorme, II, 1941, pp. 8-10). Se procuraba que fueran a poblar indios otomíes "para que, con su compañía, los indios chichimecos se hicieran más domésticos y capaces de política y de christiandad". ${ }^{37}$ De hecho, en esta colonización al norte se llevaron a indios del centro de México para pacificar a los chichimecas y enseñarles el modo de vida de los habitantes del centro, algo que fue muy común también con indios de Tlaxcala. ${ }^{38}$

Las biografías de Arnaya y Carochi parecen mostrarnos que hubo mayor movilidad durante el generalato de Claudio Acquaviva, debido a la gran importancia que dio al desarrollo de las actividades misioneras, al de Muzio Vitelleschi, cuando varias misiones obtienen un estatus de colegio, ya que tanto Arnaya como Carochi se quedaron más largas temporadas establecidos en un lugar fijo durante el gobierno de éste último. De acuerdo a un estudio del historiador Paolo Broggio sobre la identidad misionera de los jesuitas españoles en la Península Ibérica, después del generalato de Claudio Acquaviva, con la única excepción de Vicente Carafa (1646-1649), existió un menor deseo de promoción del ministerio apostólico, iniciando un proceso de sedentarización con la consolidación de una red de colegios (Broggio, 2003, pp. 239 y 256). Sin embargo, la realidad fue mucho más compleja en América, como nos lo muestran las biografías de Nueva España, ya que las misiones y los colegios siempre fueron complementarios, por lo que la movilidad del personal continuó existiendo en la provincia de México, a pesar del cambio de estatuto de muchas misiones a colegios, y la creación de varios de éstos últimos.

Las trayectorias de los padres Luis de Ahumada (1564-1629), Juan de Figueroa (1594-1659), o Diego Larios (1573-1632), nos demuestran que hubo una movilidad de personal a lo largo de la provincia similar en los dos generalatos. Así, Ahumada, quien

\footnotetext{
${ }^{36}$ Diccionario histórico de la Compañía de Jesús, I, p. 664; DBCJM IV, pp. 655-656.

${ }^{37}$ MM VII, p. 403.

${ }^{38}$ Sobre las colonizaciones tlaxcaltecas en el norte novohispano, ver Martínez Baracs (1992, pp. 195250).
} 
llegó de España, estuvo durante el generalato de Acquaviva en el colegio de Puebla (1600), ${ }^{39}$ la misión de Parras (1604), ${ }^{40}$ y el colegio de Tepotzotlán (1610-1617), ${ }^{41}$ y durante el de Vitelleschi, en el Colegio Máximo de México (1620), y el colegio de Guatemala (1626), muriendo en 1629 en la Ciudad de México. ${ }^{42}$ Por su parte, Juan de Figueroa, originario de la Nueva España, entró a Tepotzotlán en el último año del generalato de Acquaviva (1614), para luego pasar durante el de Vitelleschi al Colegio Máximo de México (1620), la misión de San Luis de la Paz (1626), el colegio de Querétaro (1632), el seminario de San Ildefonso (1638), el colegio de Guatemala (1645), el colegio de Tepotzotlán de nuevo (1650), y el colegio de San Gregorio (1653), muriendo en el colegio de Tepotzotlán en $1659 .{ }^{43}$ Por último, Diego Larios, originario también de Nueva España, estuvo durante el generalato de Acquaviva en la residencia de Tepotzotlán (1592), después en Puebla (1594), regreso a Tepotzotlán ese mismo año estuvo también en la Casa Profesa (1596), posteriormente estuvo en el Colegio Máximo (1597), en San Ildefonso (1600), en la residencia de Guadiana (1604), en la misión de Parras (1607), en la misión de los tepehuanes (1612), y otra vez en el Colegio Máximo (1614); durante el generalato de Vitelleschi, aunque tuvo menor movilidad, ésta no fue tan notoria, estando presente en el Colegio Máximo (1618), en el colegio de Guatemala (1620), en el seminario de San Ildefonso de Puebla (1626), y en el colegio de Tepotzotlán, donde finalmente fallece (1632). ${ }^{44}$

También encontramos casos de jesuitas que se movieron muy poco de las ciudades en las que estuvieron desde un principio, como Juan de Alcázar (1567-1623), proveniente de España, quien estuvo casi todo el tiempo en el Colegio Máximo de México (1592-1623), durante los gobiernos de Acquaviva y Vitelleschi, con dos únicas excepciones que estuvo en la residencia de Tepotzotlán (1595 y 1607). ${ }^{45} \mathrm{O}$ también el caso de Juan Bartolomé de Alemán (1572-1625?), también originario de España, que pasó la mayor tiempo del tiempo en el centro de México, estando primero como novicio en Puebla (1594), después pasó a la residencia de Tepotzotlán (1595), en 1600 aparece en San Ildefonso, y de 1604 a 1625 , estuvo en el Colegio Máximo. ${ }^{46}$ Otro caso similar es el del padre Pedro Nieto, originario de España, quien estuvo primero de 1585 a 1597 en el Colegio Máximo, posteriormente pasó a la residencia de Tepotzotlán sólo cuatro años, y después estuvo desde 1607 a 1637 en San Idelfonso, en la Ciudad de México, donde finalmente murió. ${ }^{47}$

Si bien los casos anteriores nos muestran a jesuitas que estuvieron sobre todo en colegios del centro del virreinato durante los dos generalatos, y que por lo tanto no vi-

\footnotetext{
${ }^{39}$ MM VI, p. 167.

${ }^{40}$ MM VIII, p. 403.

${ }^{41}$ DBCJM III, p. 145.

${ }^{42}$ DBCJM III, pp. 145-147.

${ }^{43}$ DBCJM VI, pp. 695-699.

${ }^{44}$ DBCJM VIII, pp. 292-317.

${ }^{45}$ MM IV, p. 397; MM V, p. 513; MM VII, p. 30; MM VIII, p. 381;

${ }^{46}$ MM V, p. 550; MM VI; p. 170; MM III p. 625; MM VIII, p. 382; DBCJM III, p. 267-268.

${ }^{47}$ MM II, p. 750; MM IV, p. 373; MM IV, p. 668; MM V, p. 511, 533; MM VI, p. 344; MM VII, p. 38; MM VIII, p. 392; DBCJM X, p. 508.
} 
vieron tanta movilidad, en los nuevos colegios que se abrían en zonas más apartadas de la capital, sí existió gran movilidad entre su personal. Un caso nos lo muestra el padre Esteban Corso (1573-1644), originario de Italia, quien apareció en 1607 en el colegio de Tepotzotlán, y en 1614 en la residencia de Veracruz; posteriormente durante el generalato de Vitelleschi, estuvo en el seminario de San Ildefonso en la Ciudad de México en 1620, en el colegio de Granada (Nicaragua) en 1626, y en el colegio de Guatemala entre 1632 y $1638 .^{48}$ Es posible que la movilidad que existió entre estos colegios, haya sucedido por la lejanía que tenían de la Ciudad de México, y la necesidad de personal que necesitaban, una cuestión que requiere profundizarse en futuras investigaciones.

\section{Conclusión}

La compañía de Jesús, como una Orden con identidad misionera, creó una fuerte movilidad de miembros en sus provincias, como nos lo muestra el caso de la provincia de México. Ésta tuvo una gran complejidad, siendo partícipes en ella varios actores e instituciones, tanto en España, como en Nueva España y Roma, que decidían a qué lugares y quiénes debían ser enviados a América, escogiéndose a los padres que eran enviados según las necesidades de las provincias, así como las posibilidades que había de enviarlos.

Estudiar la movilidad jesuita también nos permitió observar que, ya sea en zona de colegios o misiones, la movilidad fue continua. Si bien en los colegios del centro existió una menor movilidad, no fue así en los que se estaban abriendo en zonas apartadas a la capital del virreinato. Aunque Muzio Vitelleschi le diera mayor prioridad a los colegios, a diferencia de Claudio Acquaviva que le había dado a las misiones, y varias misiones cambiaron su estatuto por el de colegio, la movilidad de personal, aunque haya decaído un poco, continuó siendo un elemento importante en la provincia de México. De esta forma, no se observa una variación tajante entre la movilidad y la sedentarización entre los generalatos de ambos generales. Quizás en un futuro habría que hacer una comparación de la movilidad de personal entre las provincias europeas y las americanas durante estos dos generalatos, para observar si en Europa sí es más clara la diferencia entre movilidad y sedentarización entre Acquaviva y Vitelleschi, y si es así, analizar a qué se debieron esas diferencias.

\section{Referencias}

\section{Documentales y libros antiguos}

ARSI: Archivum Romanum Societatis Iesu (Roma)

ABZ: Alegre SJ, F. J. [1956 (1769-1841)]. Historia de la provincia de la Compañía de Jesús en la Nueva España, edición de Ernest Burrus S.J. y Félix Zubillaga S.J., Roma: IHSI, (3 volúmenes).

Constituciones: Loyola SJ, I. [1970 (1550)]. The Constitutions of the Society of Jesus, George E. Ganss, (ed), St. Louis: The Institute of Jesuit Sources.

\footnotetext{
${ }^{48}$ ARSI, Mex. 04, ff. 176r-176v; DBCJM V, pp. 709-710.
} 
DBCJM: Zambrano SJ, F. y Gutiérrez Casillas, J. (1961-1977). Diccionario Bio bibliográfico de la Compañía de Jesús en México, México: Buena Prensa, (volúmenes. 3-14).

DPIS: Acosta SJ, J. [1984(1576)]. De Procuranda Indorum Salute II, Luciano Peña (dirección), Madrid: CSIC.

MM: Zubillaga SJ, F. (ed) (1956-1991). Monumenta Mexicana 1571-1605, Roma: MHSI, (8 volúmenes).

RLI: Recopilación de las leyes de los Reinos de Indias (1756). Mandadas a imprimir, y publicar por la magestad católica del rey Don Carlos II. Madrid, Antonio Balbás, (4 volúmenes).

Sánchez Baquero, J. SJ [1945 (finales del siglo XVI)]. Fundación de la Compañía de Jesús en Nueva España 1571-1580, México: Editorial Patria.

\section{Bibliográficas}

Abascal Sherwell Raull, P. (2015). Tepotzotlán: la institucionalización de un colegio jesuita en la frontera chichimeca de la Nueva España (1580-1617), Tesis defendida en European University Institute (Florencia).

“"Recíbanlos con cautela y consideración: las pugnas por el poder entre la Compañía de Jesús en la Nueva España durante el generalato de Claudio Acquaviva (1581-1615), Colonial Latin American Review, (en prensa).

Borges, P. (1977). El envío de misioneros a América durante la época española. Salamanca: Universidad Pontificia.

Brading, D. (1991). The first America. The Spanish monarchy, Creole patriots, and the Liberal state. 1492- 1867. Cambridge: Cambridge University Press.

Broggio, P. (2003). La questione dell'identità missionaria nei gesuiti spagnoli del XVII secolo. Mélanges de l'École française de Rome, 115, pp. 227- 261.

Broggio, P. y Cantú, F. et.al (eds.) (2007). I gesuiti ai tempi di Claudio Acquaviva: Strategie politiche, religiose e culturali tra Cinque e Seicento. Brescia: Morcelliana.

Burrus SJ, E. (1956). Pioneer Jesuit Apostles among the Indians of New Spain (15721604). Ignatian principles put into practice. 25(1), pp. 574-597.

Catto, M. (2009). La Compagnia divisa: Il dissenso nell'ordine gesuitico tra '500 e '600. Brescia: Morcelliana.

Cuevas SJ, M. (1921). Historia de la Iglesia en México. México: Imprenta de Asilo Patricio Sanz, (4 volúmenes).

Decorme SJ, G. (1941). Obra de los jesuitas mexicanos. Época colonial, 1572-1767. México: Antigua librería Robredo de José Porrua e hijos, (2 volúmenes). 
Galán García, A. (1995). El "oficio de Indias" de Sevilla y la organización económica y misional de la Compañía de Jesús (1566-1767). Sevilla: Fundación Fondo de Cultura de Sevilla.

Maldavsky, A. (2012). Pedir las Indias: las cartas indipetae de los jesuitas europeos. siglos XVI-XVIII, ensayo historiográfico. Relaciones, 132, pp. 147-181.

(2014). Conectando territorios y sociedades. La movilidad de los misioneros jesuitas en el mundo ibérico (siglos XVI-XVIII), Historica 38(2), pp. 71-109.

Martínez Baracs, A. (1992). "Colonizaciones tlaxcaltecas”, Historia Mexicana, 43: 2, pp. 195-250.

O’Neill SJ, C. y Domínguez SJ, J. M. (dirs.) (2001). Diccionario histórico de la Compañía de Jesús: biográfico-temático. Roma/Madrid: Institutum Historicum/Universidad Pontificia de Comillas. (4 volúmenes)

Ortega Moreno, M. y Galán García. A. (2012). Quiénes son y de dónde vienen: una aproximación al perfil prosopográfico de los jesuitas enviados a Indias (15661767). En: José Martínez Millán, et.al., Los jesuitas: Religión, política y educación (siglos XVI-XVIII), Vol. III. Madrid: Universidad Pontificia de Comillas, pp. 1419-1448.

Osorio Romero, I. (1988). Antonio Rubio en la filosofía Novohispana. México: UNAM.

Romano, A. (2012). Antonio Rubio, missionnaire philosophe: Culture, savoir et évangélisation jésuite en Nouvelle-Espagne (1570-1615). En: Antonella Cagnolati (ed.), La formazione delle Élites in Europa dal Rinascimento alla Restaurazione, Roma, Publications d'Italiques, 4, pp. 151- 174.

Rusell, C. (2011). Imaging the 'indies': Italian Jesuit petitions for the overseas missions at the turn of the seventeenth century. En: Adriano Prosperi (ed.), L'Europa divisa e i nuovi mondi, vol. II, Pisa: Edizioni della Normale, pp. 179-189

Zubillaga, F. (1953). El Procurador de las Indias occidentales de la Compañía de Jesús (1574): Etapas históricas de su erección. AHSI, 22, pp. 367- 417.

(1961). Tercer concilio mexicano, 1585. Los memoriales del P. Juan de la Plaza, S.I. AHSI, 30, pp. 180-244. 